\title{
双功能电解液添加剂对锂离子电池高温高电压性能的影响
}

\author{
江依义 ${ }^{1}$, 沈 旻 $^{1}$, 宋半夏 ${ }^{1}$, 李 南 $^{1}$, 丁祥欢 ${ }^{1}$, 郭乐毅 ${ }^{2}$, 马国强 ${ }^{1,2}$
}

(1. 浙江省化工研究院有限公司锂电材料重点实验室, 杭州 310012; 2. 中国计量大学 光电材料与器件研究院, 杭州 310018)

摘 要: 三元锂离子动力电池的开发和应用受制于高温高电压条件下的容量衰减和电池产气鼓胀等技术难题。解决 这些问题一方面要注重电极材料改性和电池设计，另一方面还依赖于电解液的技术进步。本研究报道了四乙烯基硅 烷(Tetravinylsilane, TVS) 作为 $\mathrm{LiNi}_{0.6} \mathrm{Co}_{0.2} \mathrm{Mn}_{0.2} \mathrm{O}_{2}$ (NCM622)/石墨软包电池的电解液添加剂, 可以显著改善电池的高 温 $\left(45 \sim 60{ }^{\circ} \mathrm{C}\right)$ 高电压 $(4.4 \mathrm{~V})$ 性能, 包括存储和循环性能。结果表明, 电解液中含有质量分数 $0.5 \%$ TVS 的电池在 2.8 4.4 V 区间, $1 C(1 C=1.1 \mathrm{Ah})$ 倍率下循环 400 次后的容量保持率达到 $92 \%$, 而电解液中未添加 TVS 的软包电池仅 为 $82 \%$ 。进一步研究表明，一方面 TVS 高电压下优先被氧化，可以在 NCM622 颗粒表面形成耐高温的 CEI 膜，有 效抑制 NCM622 颗粒内部裂纹和过渡金属离子溶出; 另一方面, TVS 在低电位下还可以优先被还原，在石墨负极表 面聚合形成稳定的 SEI 膜，抑制电解液与负极之间的副反应。

关＼cjkstart键＼cjkstart词：高温; 软包锂离子电池; 电解液添加剂; 循环稳定性; 过渡金属离子溶出

中图分类号: TM911 文献标志码: A

\section{Effect of Dual-functional Electrolyte Additive on High Temperature and High Voltage Performance of Li-ion Battery}

\author{
JIANG Yiyi ${ }^{1}$, SHEN Min ${ }^{1}$, SONG Banxia ${ }^{1}$, LI Nan ${ }^{1}$, DING Xianghuan ${ }^{1}$, GUO Leyi ${ }^{2}$, MA Guoqiang ${ }^{1,2}$ \\ (1. Key Laboratory of Lithium-ion Battery Materials, Zhejiang Research Institute of Chemical Industry Co., Ltd., Hangzhou \\ 310012, China; 2. Institute of Optoelectronic Materials and Devices, China Jiliang University, Hangzhou 310018, China)
}

\begin{abstract}
Development and application of power lithium-ion batteries are strictly restricted by their high temperature and high voltage performance, such as capacity degradation and gas swelling, which are related to not only the modified electrode material and battery design but also the electrolyte. Herein, tetravinylsilane (TVS) was applied as electrolyte additive to improve storage and cycling performances of $\mathrm{LiNi}_{0.6} \mathrm{Co}_{0.2} \mathrm{Mn}_{0.2} \mathrm{O}_{2}(\mathrm{NCM} 622) /$ graphite pouch cell at high cutoff voltage $(4.4 \mathrm{~V})$ and high temperature $\left(45-60{ }^{\circ} \mathrm{C}\right)$. The capacity retention rate of the cell after 400 cycles $(2.8-4.4 \mathrm{~V})$ at $1 C(1 C=1.1 \mathrm{Ah})$ with mass fraction $0.5 \%$ TVS in the electrolyte is as high as $92 \%$, compared with $82 \%$ for its counterpart without TVS. On the one hand, TVS is preferentially oxidized under high voltage, contributing to the formation of a high-temperature resistant CEI (cathode electrolyte interphase) film on the surface of NCM622 particles, which effectively inhibits generation of internal cracks in NCM622 particles and dissolution of transition
\end{abstract}

收稿日期：2021-10-22；收到修改稿日期：2022-01-19; 网络出版日期：2022-03-18

基金项目: 科技厅省属科研院所扶持专项(330000210130304027003-03); 国家自然科学基金(51802300); 国家重点研发计划 (2019YFE0100200)

Zhejiang Provincial Department of Science and Technology (330000210130304027003-03); National Natural Science Foundation of China (51802300); National Key Research and Development Program of China (2019YFE0100200)

作者简介：江依义(1988-), 女，硕士. E-mail: jiangyiyi@sinochem.com JIANG Yiyi(1988-), female, Master. E-mail: jiangyiyi@sinochem.com

通信作者：马国强，高级工程师. E-mail: erguo87@163.com; maguoqiang@sinochem.com MA Guoqiang, senior engineer. E-mail: erguo87@163.com; maguoqiang@sinochem.com 
metal ions. On the other hand, TVS can also be preferentially reduced and polymerized, thus forming a stable SEI film on the surface of graphite anode, which inhibits the side reaction between the electrolyte and the negative electrode.

Key words: high temperature; lithium-ion pouch cell; electrolyte additive; cycle stability; transition metal dissolution

高能量密度、长寿命和高安全性是锂离子电池 在电动汽车领域商业化应用的前提条件 ${ }^{[1-3]}$ 。提高充 电截止电压是提升电池能量密度的有效方式之一, 以 $\mathrm{NCM} 622$ 石墨电池为例, 将充电截止电压从 $4.2 \mathrm{~V}$ 提升至 $4.45 \mathrm{~V}$, 可使电池的能量密度提升 $15 \%$ 。然 而, 电池的性能与其工作电压窗口和所处的环境温 度密切相关。一方面, 传统碳酸酯类溶剂在高电压 下易氧化分解产生气体，引发电池鼓胀 ${ }^{[4-5]}$; 在高荷 电状态下，正极材料的过渡金属离子溶出加剧，导 致电池阻抗增大、容量衰减 ${ }^{[6-7]}$ 。另一方面, 有研究 表明 ${ }^{[2]}$ 当电池工作温度超过 $60{ }^{\circ} \mathrm{C}$ 时, 电池的电化 学性能显著恶化, 甚至由此引发安全问题。因此, 抑 制高温高电压条件下电极和电解液界面之间的一系 列副反应并保持其界面稳定，具有重要意义 ${ }^{[8]}$ 。

研究表明 ${ }^{[9]}$, 采用功能性成膜添加剂在电极表 面构建稳定的界面保护膜是一种经济有效的方法。 常温下，碳酸酯类添加剂如碳酸亚乙烯酯(Vinylene carbonate, $\mathrm{VC})^{[10-11]}$ 、氟代碳酸乙烯酯(Fluoroethylene carbonate, FEC $)^{[12]}$ 等, 参与形成正极电解液界面 (Cathode Electrolyte Interphase, CEI)膜，可以有效抑 制高电压条件下电解液在正极表面的氧化分解。硅 烷类添加剂如三(三甲基硅烷)嗍酸酯 ${ }^{[13-14]}$ 和三(三甲 基 硅 烷) 磷 酸 酯 (Tris(trimethylsilyl) phosphate,

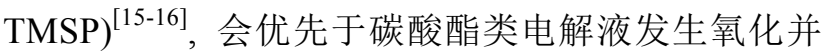
参与形成稳定的 CEI 膜, 从而提高高电压条件下正 极界面的稳定性。然而，上述添加剂应用于高温环 境(测试工况通常指 45 60 ${ }^{\circ} \mathrm{C}$ ) 时具有一定的局限性, 如 $\mathrm{VC}$ 在高温高电压下的循环性能较差, 实际应用 中需和其它添加剂复合使用。 FEC 相比 VC 虽可提 高氧化稳定性，但在高温条件下稳定性下降，容易 发生分解产生更多的氢氟酸 ${ }^{[17]}$, 进而造成更加严峻 的正极过渡金属离子溶出问题。含 TMSP 的电解液 在高温存储过程中易与六氟磷酸锂反应, 氧化后参 与形成的 CEI 膜组分中 $\mathrm{Li}_{x} \mathrm{PF}_{y} \mathrm{O}_{z}$ 含量较低, 降低了 电池的电化学性能 ${ }^{[18]}$ 。此外常见的高温型添加剂 1,3-丙烷磺内酯 (1,3-propanesulfonate, PS) $)^{[19-20]}$ 虽然 可以在正极表面生成如 $\mathrm{ROSO}_{2} \mathrm{Li}$ 等对过渡金属离 子具有强螯合能力的含硫物质，从而达到有效抑制 过渡金属离子溶出的目的, 但是 PS 是已知的强致 癌物，已经被列入欧洲化学品注册、评估、许可和 限制法规的管制清单, 使用规模和范围受到严格限
制。因此, 目前亟需开发一种新型成膜添加剂, 用于 提升电极电解液界面在高电压下的高温稳定性。

为解决上述问题, 本研究系统探索了一种新型 电解液添加剂 TVS 对 NCM622/石墨电池性能的影 响。不同充电截止电压下电池高温存储性能和存储 后过渡金属离子溶出量等测试方法表明 TVS 添加 剂可以提升 $4.4 \mathrm{~V}$ 下软包电池的高温存储稳定性。 利用电池循环寿命测试及循环后对称电池阻抗测试 等电化学表征手段, 探究 TVS 添加剂对软包电池 $45{ }^{\circ} \mathrm{C}$ 循环稳定性提升的影响。进一步采用 $\mathrm{X}$ 射线 光电子能谱分析正负极活性材料与电解液之间的界 面变化, 初步得出 TVS 改善电池性能的工作机理。

\section{1 实验方法}

\section{1 电解液和电池}

TVS(99\%)从阿拉丁试剂(上海)有限公司购得, 碳酸乙烯酯(Ethylene carbonate, EC), 碳酸甲乙酯 (Ethylmethyl carbonate, EMC), 碳酸二乙酯(Diethyl carbonate, DEC), 六氟磷酸锂(Lithium hexafluorophosphate, $\mathrm{LiPF}_{6}$ ) 等电池级原料均由浙江中蓝新能源 科技有限公司提供。对照组(Base)电解液为含 $1 \mathrm{~mol} / \mathrm{L}$ $\mathrm{LiPF}_{6}$ 的 $\mathrm{EC} / \mathrm{EMC} / \mathrm{DEC}$ (质量比 $3: 5: 2$ ) 溶液, 实验 组(TVS) 在对照组中添加质量分数 $0.5 \%$ 的 TVS, 在 无水无氧手套箱中完成电解液配制。NCM622/石墨 软包电池电芯 $(1.1 \mathrm{Ah}$, 无电解液, 外壳尺寸 $100 \mathrm{~mm} \times$ $65 \mathrm{~mm} \times 2 \mathrm{~mm}$ ) 由芜湖天亲新能源科技有限公司(中 国)制造(详见补充材料)。每个电池电解液注液量 $(4.0 \pm 0.05) \mathrm{g}$ 。电池经化成、真空密封后待用。

对称电池的制作流程如图 1 所示, 在手套箱中 拆解电池, 将双面涂覆的正极片和负极片分别裁剪 成 $\phi 12 \mathrm{~mm}$ 的圆片, 以正极/隔膜/正极或负极/隔膜/ 负极的形式组装成纽扣对称电池, 并注入 $60 \mu \mathrm{L}$ 对 照组电解液，用于测试循环前后的正、负极阻抗。

\section{2 电化学性能测试}

采用 Autolab 电化学工作站测试电池的电化学 阻抗谱(Electrochemical Impedance Spectroscopy, EIS)(100 mHz 100 kHz, $5 \mathrm{mV})$ 。采用英国 Solartron (1470E) 电化学工作站测试电解液的线性扫描伏安 


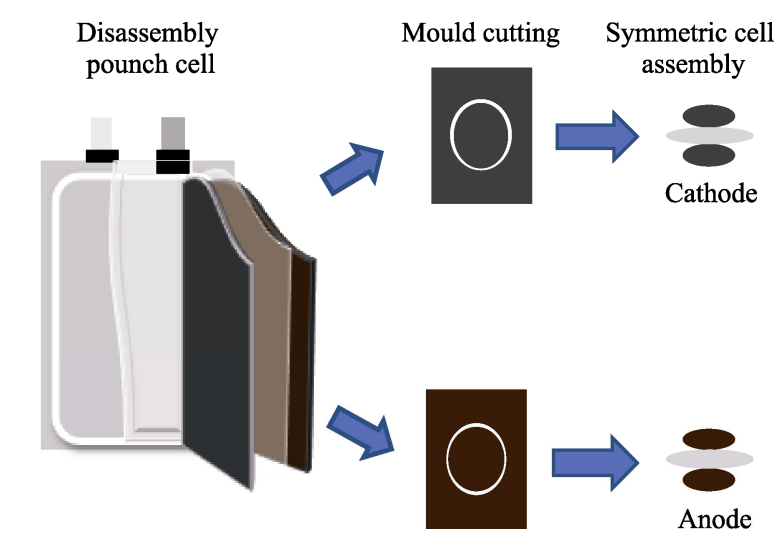

图 1 对称电池组装流程图

Fig. 1 Schematic procedure for preparing the symmetric cell

法(Linear Sweep Voltammetry, LSV)曲线(扫描速率 $0.1 \mathrm{mV} / \mathrm{s})$ 。采用新威测试柜 $(\mathrm{CT}-3008 \mathrm{~W})$ 测试电池充 放电性能, 电池化成倍率为 $0.2 C(1 C=1.1 \mathrm{Ah})$ 。在 $45{ }^{\circ} \mathrm{C}$ 下, 以 $1 C$ 倍率在 $2.8 \sim 4.4 \mathrm{~V}$ 电压区间进行电池 循环测试。

电池存储测试 在室温条件下以 $0.33 C$ 倍率充 电至所需的充电截止电压, 在 $60{ }^{\circ} \mathrm{C}$ 环境存储 $14 \mathrm{~d}$ 后, 以 $0.33 C$ 倍率充电和 $1 C$ 倍率放电充放电 3 周获 取稳定的放电容量。采用高精度恒温密度测试仪(杭 州金迈仪器有限公司, DH-300G-T)测试电池体积变 化; 采用内阻仪(日置 HIOKI, BT354)测量电压和内 阻; 采用计算公式(S1 S4) 评估电池存储前后的体 积变化率(Swelling rate)、内阻变化率(ACR change rate)、自放电率 $(K)$ 和容量恢复率(Capacity recovery rate)(详见补充材料)。

\section{3 化学分析和材料表征}

采用气相色谱(Agilent 990) 分析存储后电池的 气体成分; 采用电感耦合等离子体原子发射光谱仪 (Perkin Elmer, Avio 200) 测试存储后电池的过渡金 属元素含量。采用扫描电子显微镜(Scanning Electron Microscope, SEM, 日本 HITACHI 公司 SU 8010 型)
和 $\mathrm{X}$ 射线光电子能谱仪 (X-ray Photoelectron Spectrophotometer, XPS，美国 Physical Electronics 公司 Quantum 2000 型)分别分析电池的正负极形貌 和元素价态。

\section{2 结果与讨论}

\subsection{TVS 添加剂的氧化还原行为研究}

如图 2 所示, 对电解液进行 LSV 测试。结果显 示(图 2(a)), 对照组从 $5.0 \mathrm{~V}$ 开始发生氧化分解, 含 TVS 的实验组则在 $4.3 \mathrm{~V}$ 处出现优先于溶剂的反应 峰, 证实 TVS 参与了正极氧化反应。此外, 进一步 比较以 NCM622 作为工作电极的循环伏安(Cyclic Voltammetry, CV)曲线(图 S1), 实验组第一次扫描曲 线在 $3.6 \mathrm{~V}$ 出现氧化电流, 且峰值电流明显低于对 照组; 在第二次扫描过程中, 实验组和对照组 $\mathrm{CV}$ 曲线重叠。根据 CV 测试结果, TVS 优先于溶剂发生 氧化反应, 参与正极成膜, 有助于提高电极稳定性。 在图 2(b)所示以石墨为工作电极的 LSV 还原曲线中, 对照组在 $0.5 \mathrm{~V}$ 出现了还原峰, 对应 $\mathrm{EC}$ 的还原分 解 ${ }^{[4,21]}$, 而实验组在 $0.5 \mathrm{~V}$ 处的电流明显减小, 表明 TVS 可以抑制 EC 还原反应, 改善电解液稳定性, 有助于负极成膜，延长电池服役期限。

\section{2 高温存储性能分析}

为研究 TVS 作为电解液添加剂对高电压 NCM622/石墨电池存储性能的影响, 将含不同电解 液的 5 组电池分别充电至不同截止电压(4.2、4.3、 4.35、4.4、4.45 V)后在 $60{ }^{\circ} \mathrm{C}$ 中存储 $14 \mathrm{~d}$, 测试电 池存储后的体积膨胀率、内阻增长率、 $K$ 值变化率 和容量恢复率, 如图 3(a,b)所示。随着充电截止电 压升高, 对照组电池的高温存储稳定性逐渐下降, 如 体积膨胀率从 $0.6 \%(4.2 \mathrm{~V})$ 增加至 $20 \%(4.4 \mathrm{~V})$, 内阻 变化率从 6\% (4.2 V)增加至 47\% (4.4 V)。这说明充
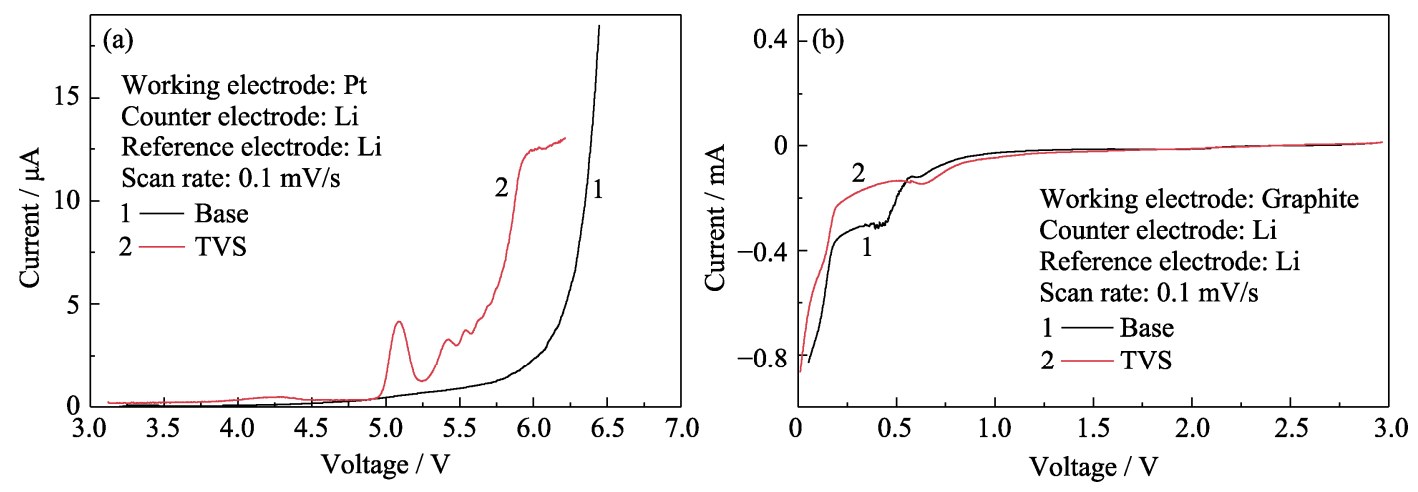

图 2 对照组和实验组电解液的 $\operatorname{LSV}(\mathrm{a})$ 氧化和(b)还原曲线

Fig. 2 LSV curves of (a) oxidation and (b) reduction of electrolytes with and without TVS 
电截止电压升高造成活性材料与电解液界面的稳定 性降低 ${ }^{[22]}$ 。与对照组电池相比, 在 $4.4 \mathrm{~V}$ 充电截止 电压下，实验组电池经相同条件存储后的体积膨胀 率(7\%)和内阻增长率(22\%)得到显著改善。

电池自放电是一种由电解液分解驱动, 伴随电 子得失和 $\mathrm{Li}^{+}$在电极界面再嵌入的现象 ${ }^{[23]}$, 可由此 评估电极界面稳定性。如图 3(b)所示, 相比于对照 组电池, 实验组电池经 $4.4 \mathrm{~V}, 60{ }^{\circ} \mathrm{C}$ 存储 $14 \mathrm{~d}$ 后的自 放电率由 $17.4 \mathrm{mV} / \mathrm{d}$ 降低至 $12.9 \mathrm{mV} / \mathrm{d}$, 说明 TVS 抑制了电解液分解, 减少了活性锂损失。该现象在 可逆容量恢复率测试中得到进一步证实, 以 $4.4 \mathrm{~V}$ 存储条件为例，电池的容量恢复率从 $84 \%$ 提升至 $90 \%$ 。图 3(c) 进一步对比了以 $0.33 \mathrm{C}$ 倍率充电至 $4.4 \mathrm{~V}$ 的对照组和实验组电池在高温存储前后的充放电曲 线, 可知两组电池在存储前初始容量几乎相等(约 $1100 \mathrm{mAh}$ ), 添加质量分数 $0.5 \%$ TVS 并未影响 $\mathrm{NCM} 622$ /石墨电池的初始容量。经过 $60{ }^{\circ} \mathrm{C}$ 存储后, 对照组电池的充、放电容量分别衰减至 928 和 $927 \mathrm{mAh}$, 而这种衰减变化在实验组电池(充、放电 容量均为 $1003 \mathrm{mAh}$ )中得到了有效抑制。

过渡金属离子从正极表面溶出, 经电解液扩散, 沉积在负极表面, 是造成锂离子电池高温存储性能

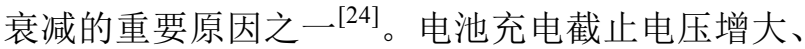
温度升高及电解液中氢氟酸含量增加均会加剧过渡 金属离子的溶出 ${ }^{[25]}$ 。溶出的过渡金属离子迁移至负 极后嵌入负极电解液界面(Solid Electrolyte Interphase, $\mathrm{SEI})$ 膜，催化锂离子与 $\mathrm{EC}$ 反应，造成活性锂损失， 最终导致电池容量衰减 ${ }^{[26]}$ 。因此, 构建高温稳定的 电极电解液界面，减少过渡金属离子的溶出及其在 负极的沉积显得尤为重要。对上述充电至 $4.4 \mathrm{~V}$ 经 高温存储后的电池进行金属离子溶出量测试, 结果 如表 1 所示。从表中可以看出, 相比对照组电池, 实 验组电池负极上检测到 Ni、Co、Mn 含量均显著降 低, 表明 TVS 作为添加剂形成的正极保护膜具有较 好的热稳定性, 可以有效抑制 $4.4 \mathrm{~V}$ 下软包电池高
温存储后的过渡金属离子溶出。其中，负极上检测 到 $\mathrm{Mn}$ 含量(质量分数 $0.0130 \%$ ) 高于 $\mathrm{Ni}$ 含量(质量分 数 $0.0090 \%)$, 这主要是由于温度以及充电截止电压 升高加速了 $\mathrm{Mn}$ 溶出, 和 Gasteigera 等 ${ }^{[25]}$ 的报道结 果一致。此外, 有研究表明 ${ }^{[26]}$ 负极 SEI 膜中 Mn 含 量与电池容量损失相关性大于 Co 和 $\mathrm{Ni}$ 含量, 含 TVS 添加剂的实验组电池可以有效抑制以 $\mathrm{Mn}$ 为代 表的过渡金属离子在负极的沉积, 从而提升实验组 电池高温存储后的容量恢复率。

表 1 对照组和实验组电池经 $4.4 \mathrm{~V} 、 60{ }^{\circ} \mathrm{C}$ 存储 $14 \mathrm{~d}$ 后 负极上沉积的过渡金属离子含量(质量分数)

Table 1 Mass fractions of Ni, Co and Mn ions deposited on anodes from pouch cell with and without TVS in electrolyte stored at cutoff potential of $4.4 \mathrm{~V}$ and temperature of $60{ }^{\circ} \mathrm{C}$ for $14 \mathrm{~d}$

\begin{tabular}{cccc}
\hline Sample & $\mathrm{Ni} /\left(\times 10^{-4}, \%\right)$ & $\mathrm{Co} /\left(\times 10^{-4}, \%\right)$ & $\mathrm{Mn} /\left(\times 10^{-4}, \%\right)$ \\
\hline Base & 90 & 21 & 130 \\
TVS & 35 & 4 & 69 \\
\hline
\end{tabular}

在高温存储中, SEI 膜因稳定性变差而受热分解, 电解液中的 $\mathrm{EC}$ 则在负极表面分解产生 $\mathrm{C}_{2} \mathrm{H}_{4} 、 \mathrm{CO}$ 和 $\mathrm{CH}_{4}$ 等气体 ${ }^{[27]}$ 。电池充电截止电压的升高, 一方面加 剧了正极活性氧析出, 使得 $\mathrm{EC}$ 被氧化分解产生 $\mathrm{CO}_{2}$; 另一方面使得 EC 更容易在正极表面失电子被氧化 为 $\mathrm{R}-\mathrm{H}^{+}$, 并扩散至负极表面被还原成 $\mathrm{H}_{2}{ }^{[5]}$ 。表 $\mathrm{S} 1$ 分析了电池存储后的气体成分和含量, 相比对照组 电池, 实验组电池的 $\mathrm{C}_{2} \mathrm{H}_{4} 、 \mathrm{CO}$ 和 $\mathrm{CH}_{4}$ 等气体分别从 67.0、393.3、253.2 $\mu \mathrm{L}$ 降低至 1.1、9.2、4.8 $\mu \mathrm{L}$, 表 明 TVS 构建的 SEI 膜稳定性更高，抑制了EC 在负极 的还原分解。 $\mathrm{CO}_{2}$ 含量从 $209.3 \mu \mathrm{L}$ 显著减少至 $2.2 \mu \mathrm{L}$, 表明 TVS 增强了正极 CEI 膜的稳定性，抑制了 EC 的氧化分解。而 SEI 膜和 CEI 膜稳定性增强的同时, $\mathrm{EC}$ 在正负极的氧化还原分解也得到了抑制，使得 $\mathrm{H}_{2}$ 含量从 $17.6 \mu \mathrm{L}$ 减少至 $0.2 \mu \mathrm{L}$ 。上述测试结果证实 TVS 作为电解液添加剂有效改善了 NCM622/石墨软 包电池在 $4.4 \mathrm{~V}$ 高电压下的高温存储性能。
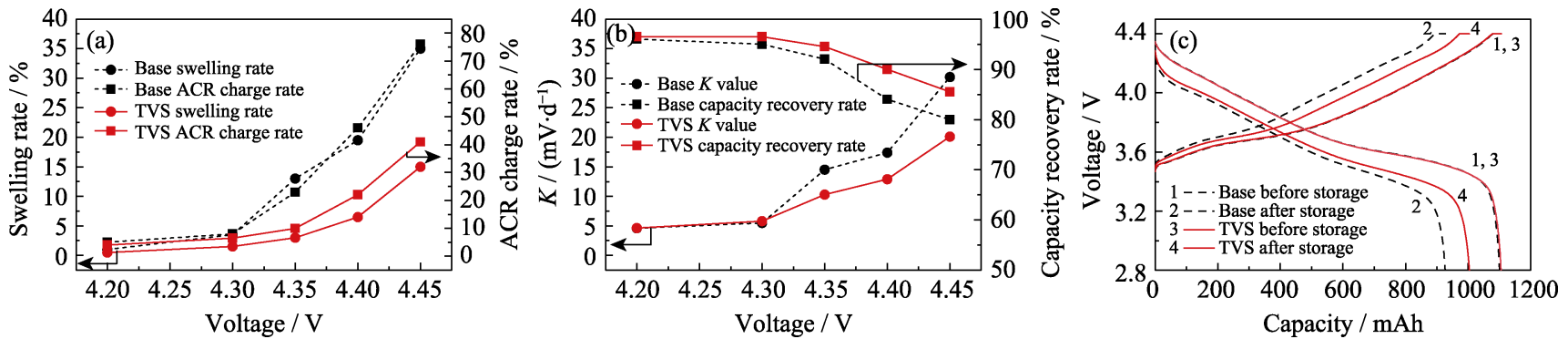

图 3 对照组和实验组电池经 $60{ }^{\circ} \mathrm{C}$ 存储 $14 \mathrm{~d}$ 后的(a)体积和内阻变化率、(b)自放电率和容量恢复率以及(c)充放电曲线

Fig. 3 (a) Gas swelling rates and ACR change rates, (b) $K$ values and capacity recovery rates, (c) charge and discharge curves of pouch cells with and without TVS in electrolytes after storage at $60{ }^{\circ} \mathrm{C}$ for $14 \mathrm{~d}$ 


\section{3 高温循环性能分析}

图 4 为对照组和实验组电池在 $45{ }^{\circ} \mathrm{C} 、 1 C$ 和 2.8 4.4 V 条件下的循环性能。根据实验结果分析, 对照组电池容量快速衰减, 循环 400 周后容量保持 率仅为 $82 \%$, 而在电解液中添加质量分数 $0.5 \%$ 的 TVS 后, 电池容量衰减被明显抑制, 容量保持率提 升至 92\% (图 4(a))。这表明 TVS 添加剂有利于构建 稳定的电极电解液界面膜, 提高电池循环稳定性, 减少容量损失。图 4(b)展示了充电平均电压与放电 平均电压的压差 $(\Delta V)$ 与循环周数的关系, $\Delta V$ 越小意 味着循环过程中极化增长越小, 电池阻抗增长越 小。相比于对照组电池, 实验组电池的 $\Delta V$ 更稳定。 图 S2 $(a, b)$ 分别展示了对照组电池和实验组电池在循 环 $1 、 100 、 200 、 300$ 和 400 周后的 $\mathrm{d} Q / \mathrm{d} V$ 曲线。 对照组电池在循环 400 周后, 石墨嵌锂峰 ${ }^{[7]}$ 从 $3.417 \mathrm{~V}$ 偏移至 $3.492 \mathrm{~V}$, 过渡金属氧化峰 ${ }^{[28]}$ 从 $3.646 \mathrm{~V}$ 偏移 至 $3.683 \mathrm{~V}$, 峰形的正向偏移说明循环过程中极化增 大。而实验组电池循环 400 周后峰形重叠, 无明显 偏移(图 S2(b)), 表明 TVS 添加剂可抑制电池循环过 程中的极化增长, 增强氧化还原过程的可逆性。

为了更好地理解电池在循环过程的性能衰减机 理, 研究 TVS 添加剂对电极界面和电池电化学性能 的影响, 对软包全电池及循环 100 周前后拆解组装 成的负极和正极对称纽扣电池进行 EIS 测试, 结果 如图 4(c e e) 所示。高频区与实轴的交点为溶液电阻 $\left(R_{\mathrm{S}}\right)$, 高频区的半圆为界面阻抗 $\left(R_{\mathrm{sei}}\right)$, 中频区的半圆
为电荷转移阻抗 $\left(R_{\mathrm{ct}}\right)$, 低频区的斜线为 Warburg 阻 抗 $(W)$ 。将上述 EIS 数据通过对应的等效电路进行拟 合, 得到的阻值如表 $\mathrm{S} 2$ 所示。两组全电池初始 $R_{\mathrm{S}}$ 相差不大, 对照组电池经循环后 $R_{\mathrm{S}}$ 增加至 $46.7 \mathrm{~m} \Omega$, 而实验组电池为 $38.5 \mathrm{~m} \Omega$ 。全电池循环前后的 $R_{\mathrm{ct}}$ 差异更为明显，虽然实验组电池的初始 $R_{\mathrm{ct}}(25.8 \mathrm{~m} \Omega)$ 明显高于对照组电池 $(14.2 \mathrm{~m} \Omega)$, 但循环后对照组电 池的 $R_{\mathrm{ct}}$ 增加了 $5.1 \mathrm{~m} \Omega$, 而实验组电池的 $R_{\mathrm{ct}}$ 无增加。 进一步, 根据实验组电池制备的负极对称电池 EIS 测试结果, 发现 TVS 添加剂造成电池初始 $R_{\mathrm{ct}}$ 较高 的原因主要来源于负极, 推测与负极成膜机制有 关。此外, 对照组电池经循环 100 周后负极 $R_{\text {sei }}$ 增加 了 $12.4 \mathrm{~m} \Omega$, 而相同条件下实验组电池的负极 $R_{\mathrm{sei}}$ 仅增加了 $2.1 \mathrm{~m} \Omega$, 表明 TVS 添加剂有助于在负极表 面构筑稳定的 SEI 膜。正极对称电池 EIS 数据显示, 循环 100 周后实验组电池的正极 $R_{\mathrm{ct}}(18.1 \mathrm{~m} \Omega)$ 和 $R_{\mathrm{sei}}$ $(100.4 \mathrm{~m} \Omega)$ 均小于对照组电池的正极 $R_{\mathrm{ct}}(26.7 \mathrm{~m} \Omega)$ 和 $R_{\text {sei }}(144.3 \mathrm{~m} \Omega)$, 表明 TVS 添加剂提高了 NCM622 电 极与电解液的兼容性。其中, 正极对称电池高频区 的 $R_{\mathrm{sei}}$ 较高是由于对称电池使用了双面涂覆的活性 材料, 导致纽扣电池壳体的金属触点与活性材料的 界面接触电阻较高 ${ }^{[29]}$, 而石墨活性材料的导电性较 好, 对负极对称电池高频区的 $R_{\text {sei }}$ 影响较小。

\section{4 正负极界面影响研究}

本研究采用 SEM 和 XPS 探究 TVS 作为电解液 添加剂对电池正负极界面形貌和组分稳定性的影
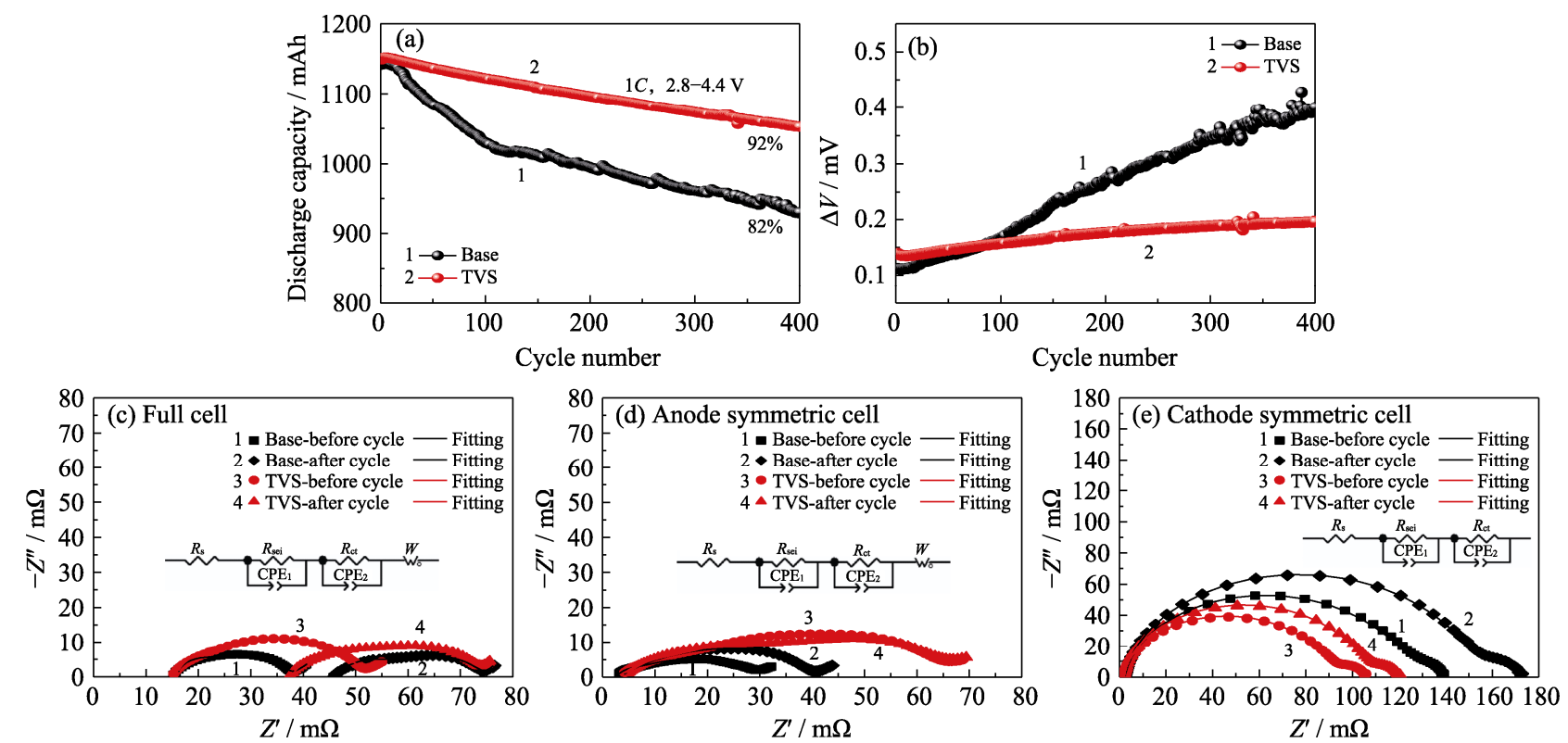

图 4 对照组和实验组电池在 $45{ }^{\circ} \mathrm{C}$ 的循环性能

Fig. 4 Cycling performance of pouch cells with and without TVS in electrolytes at $45{ }^{\circ} \mathrm{C}$ (a) Discharge capacity and (b) $\Delta V v s$ cycle number; EIS plots of (c) pouch full cells, (d) graphite/graphite symmetric cells and (e) NCM622/NCM622 symmetric cells before and after 100 cycles 
响。图 5(a,b)分别是对照组电池和实验组电池循环 100 周后正极 SEM 照片。在电解液中引入 TVS 后, 实验组电池经过 100 周循环后正极表面依旧光滑平 整，未出现对照组电池中的正极颗粒裂纹，表明 TVS 可以提高正极界面在高电压高温下的稳定性, 抑制正极材料与电解液之间的界面副反应，从而减 少电池性能衰减。图 5(c)为电池经化成和 $1 C$ 循环 10 圈后的正极表面 XPS 图谱，包括 C1s、O1s、F1s、 $\mathrm{Si} 2 \mathrm{p}$ 能谱。 $\mathrm{C} 1 \mathrm{~s}$ 谱显示, 材料表面可以检测到石墨 导电剂 $(284.8 \mathrm{eV})$ 和聚偏氟乙烯黏结剂 $(290.3 \mathrm{eV})$ 信 号 ${ }^{[20]}$ 。O $\mathrm{O} 1 \mathrm{~s}$ 谱中 $530 \mathrm{eV}$ 处的峰对应材料中的金属 $\mathrm{M}-\mathrm{O}$ 键 ${ }^{[20,30]}$ 。 F1s 谱中 $684.5 \mathrm{eV}$ 处的峰对应 Li-F 键 ${ }^{[20]}, 686.8 \mathrm{eV}$ 处的峰对应 $\mathrm{Li}_{x} \mathrm{PF}_{y} \mathrm{O}_{z}{ }^{[4]}$ 。 $\mathrm{Si} 2 \mathrm{p}$ 图谱中 102.0 和 $100.0 \mathrm{eV}$ 处的峰分别对应 $\mathrm{Si}-\mathrm{O}$ 和 $\mathrm{Si}-\mathrm{C}$ 键 ${ }^{[14]}$ 。 相比于对照组电池, 实验组电池的正极界面中含有 机硅组分, 表明添加剂 TVS 参与了正极成膜, 且 $\mathrm{M}-\mathrm{O}$ 信号响应强度降低, 表明 TVS 形成的 CEI 膜 更为致密 ${ }^{[20,30]}$ 。与此同时, 实验组电池正极表面 $\mathrm{Li}_{x} \mathrm{PO}_{y} \mathrm{~F}_{z}$ 含量降低, 表明添加剂 TVS 抑制了电解液 分解 ${ }^{[4]}$ 。这些结果进一步证实了 TVS 可以构建稳定 的 CEI 界面。此外, 本研究还对比了添加剂 TVS 对 石墨负极界面形貌和组分的影响, 如图 S3 所示, 实 验组电池循环 100 周后的负极表面粗粮程度显著降
低，且通过 XPS 谱图(图 S3(c))分析发现，仅实验组 电池在 Si2p 谱中存在 Si 的特征峰, 结合 LSV 和对 称电池 EIS 的测试结果, 说明 TVS 也有助于构建稳 固的 SEI 膜，进而提高电池的高温高电压稳定性。

根据测试结果, 本研究分析了 TVS 作为电解液 添加剂对电池性能提升的作用机理 ${ }^{[4]}$, 如图 S4 所 示。根据电解液的 LSV 氧化曲线(图 2(a))在 5.0 和 $5.5 \mathrm{~V}$ 等处的氧化峰, 可知 TVS 可发生多级氧化反 应，推测 TVS 不仅可以通过碳碳双键发生失电子氧 化反应，还可与氧自由基结合形成新的有机硅化合 物, 这与正极 $\mathrm{Si} 2 \mathrm{p}$ XPS 谱图(图 5(c))中同时出现 $\mathrm{Si}-\mathrm{C}$ 和 $\mathrm{Si}-\mathrm{O}$ 信号相吻合。该有机硅化合物参与形 成稳定的 CEI 膜, 覆盖在正极材料表面, 有效抑制 了电解液的氧化分解，并防止过渡金属离子溶出, 提高了正极材料稳定性。同时根据电解液的 LSV 还 原曲线(图 2(b))判断，添加剂 TVS 可抑制 EC 还原反 应, 结合 XPS 谱图(图 S3(c))中观察到的 Si-C 信号, 推测 TVS 在负极以分子间的自主聚合反应为主。通 过还原聚合, TVS 在石墨负极生长出致密的网络状 保护层，抵御高温存储过程中过渡金属离子对负极 活性材料的侵蚀破坏，并抑制循环过程中负极阻抗 增大。因此, TVS 作为双功能电解液添加剂显著改 善了锂离子电池的高温高电压性能。
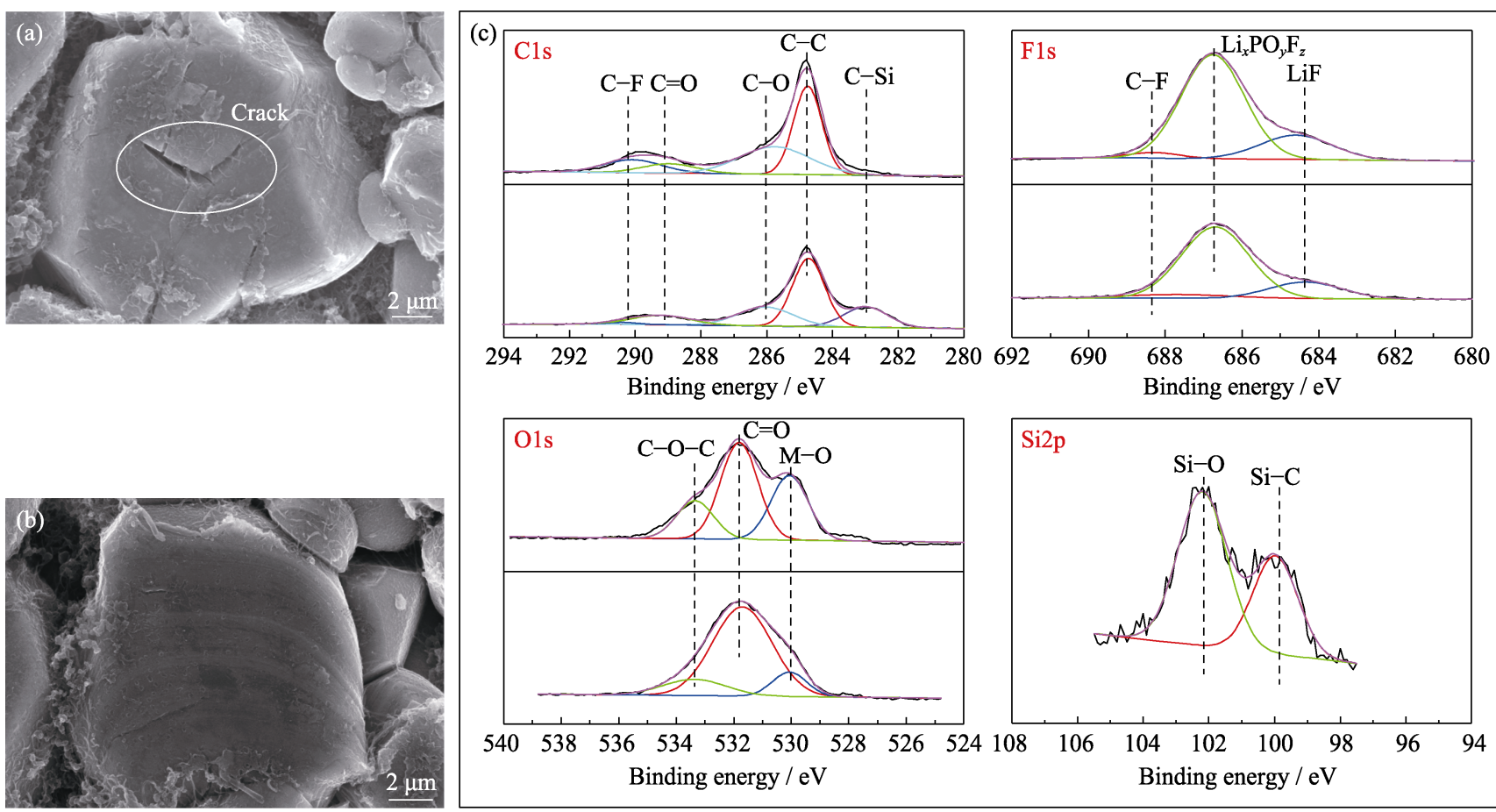

图 5 (a)对照组和(b)实验组电池循环 100 周后正极 SEM 照片, (c)对照组和实验组电池循环 10 周后正极表面 XPS 分谱

Fig. 5 SEM images of cathodes from pouch cells (a) without and (b) with TVS in electrolytes after 100 cycles;

(c) XPS spectra of cathodes from pouch cells without and with TVS in electrolytes after 10 cycles 


\section{3 结论}

\section{本研究证明了 TVS 是一种有效的电解液添加} 剂, 通过同时参与正、负极表面成膜, 提升了 NCM622/石墨软包电池的高温高电压性能。高温存 储测试表明, 电解液中加入 TVS 可有效降低电池经 $4.4 \mathrm{~V}, 60{ }^{\circ} \mathrm{C}$ 存储后的产气膨胀率(降低 $13 \%$ )和内阻 增长率(降低 $25 \%$ ), 提高了容量恢复率(提升 $6 \%$ )。 循环寿命测试表明, TVS 添加剂提升了电池 $45{ }^{\circ} \mathrm{C}$ 循环稳定性, $1 C$ 循环 400 周后容量保持率由 $82 \%$ 提 高至 $92 \%$ 。TVS 添加剂成功抑制了电解液在高电位 下的分解产气和正极过渡金属离子的溶出与沉积行 为, 并有利于保持电极良好的形貌, 显著抑制了循 环中阻抗增长。本研究不仅有助于理解电解液添加 剂在商业化锂离子电池中的作用效果和机理, 而且 可以指导设计高效电解液及添加剂体系, 为未来高 能量密度电池体系的开发和应用提供参考。

\section{补充材料}

本文相关补充材料可登陆 https://doi.org/ $10.15541 / \mathrm{jim} 20210653$ 查看。

\section{参考文献:}

[1] ZENG X, LI M, EL-HADY D A, et al. Commercialization of lithium battery technologies for electric vehicles. Advanced Energy Materials, 2019, 9(27): 1900161.

[2] WANG C, OUYANG L, FAN W, et al. Citraconic anhydride as an electrolyte additive to improve the high temperature performance of $\mathrm{LiNi}_{0.6} \mathrm{Co}_{0.2} \mathrm{Mn}_{0.2} \mathrm{O}_{2}$ /graphite pouch batteries. Journal of Alloys and Compounds, 2019, 805: 757-766.

[3] WANG C, YU L, FAN W, et al. Lithium difluorophosphate as a promising electrolyte lithium additive for high-voltage lithium-ion batteries. ACS Applied Energy Materials, 2018, 1(6): 2647-2656.

[4] ZHAO W, ZHENG B, LIU H, et al. Toward a durable solid electrolyte film on the electrodes for Li-ion batteries with high performance. Nano Energy, 2019, 63: 103815.

[5] JUNG R, METZGER M, MAGLIA F, et al. Chemical versus electrochemical electrolyte oxidation on NMC111, NMC622, NMC811, LNMO, and conductive carbon. Journal of Physical Chemistry Letters, 2017, 8(19): 4820-4825.

[6] XIE K, ZHENG C, LI Y, et al. Storage aging mechanism of $\mathrm{LiNi}_{0.8} \mathrm{Co}_{0.15} \mathrm{Al}_{0.05} \mathrm{O}_{2} /$ graphite Li-ion batteries at high state of charge. Journal of Inorganic Materials, 2021, 36(2): 175-180.

[7] JUNG R, METZGER M, MAGLIA F, et al. Oxygen release and its effect on the cycling stability of $\mathrm{LiNi}_{x} \mathrm{Mn}_{y} \mathrm{Co}_{z} \mathrm{O}_{2}(\mathrm{NMC})$ cathode materials for Li-ion batteries. Journal of The Electrochemical Society, 2017, 164(7): A1361-A1377.

[8] FAN X, WANG C. High-voltage liquid electrolytes for Li batteries progress and perspectives. Chemical Society Reviews, 2021, 50(18): 10486-10566.

[9] ZHAO D, WANG J, LU H, et al. Tailoring interfacial architecture of high-voltage cathode with lithium difluoro(bisoxalato) phosphate for high energy density battery. Journal of Power Sources, 2020, 456: 228006

[10] LEE W J, PRASANNA K, JO Y N, et al. Depth profile studies on nickel rich cathode material surfaces after cycling with an electrolyte containing vinylene carbonate at elevated temperature.
Physical Chemistry Chemical Physics, 2014, 16(32): 17062-17071.

[11] MICHAN A L, PARIMALAM B S, LESKES M, et al. Fluoroethylene carbonate and vinylene carbonate reduction: understanding lithium-ion battery electrolyte additives and solid electrolyte interphase formation. Chemistry of Materials, 2016, 28(22): 8149-8159.

[12] MARKEVICH E, SALITRA G, FRIDMAN K, et al. Fluoroethylene carbonate as an important component in electrolyte solutions for high-voltage lithium batteries: role of surface chemistry on the cathode. Langmuir, 2014, 30(25): 7414-7424.

[13] LI J, XING L, ZHANG R, et al. Tris(trimethylsilyl)borate as an electrolyte additive for improving interfacial stability of high voltage layered lithium-rich oxide cathode/carbonate-based electrolyte. Journal of Power Sources, 2015, 285: 360-376.

[14] WANG K, XING L, ZHU Y, et al. A comparative study of Si-containing electrolyte additives for lithium ion battery: which one is better and why is it better. Journal of Power Sources, 2017, 342: 677-684.

[15] DENG B, SUN D, WAN Q, et al. Review of electrolyte additives for ternary cathode lithium-ion battery. Acta Chimica Sinica, 2018, 76(4): 259

[16] LIAO X, ZHENG X, CHEN J, et al. Tris(trimethylsilyl)-phosphate as electrolyte additive for self-discharge suppression of layered nickel cobalt manganese oxide. Electrochimica Acta, 2016, 212: 352-359.

[17] KIM K, PARK I, HA S Y, et al. Understanding the thermal instability of fluoroethylene carbonate in $\mathrm{LiPF}_{6}$-based electrolytes for lithium ion batteries. Electrochimica Acta, 2017, 225: 358-368.

[18] QI X, TAO L, HAHN, H, et al. Lifetime limit of tris(trimethylsilyl) phosphite as electrolyte additive for high voltage lithium ion batteries. RSC Advance, 2016, 6(44): 38342-38349.

[19] OH J, KIM J, LEE Y M, et al. Effects of vinylene carbonate and 1,3-propane sultone on high-rate cycle performance and surface properties of high-nickel layered oxide cathodes. Materials Research Bulletin, 2020, 132: 111008.

[20] XU M, LI W, LUCHT B L. Effect of propane sultone on elevated temperature performance of anode and cathode materials in lithiumion batteries. Journal of Power Sources, 2009, 193(2): 804-809.

[21] WANG Y, NAKAMURA S, UE M, et al. Theoretical studies to understand surface chemistry on carbon anodes for lithium-ion batteries: reduction mechanisms of ethylene carbonate. Journal of the American Chemical Society, 123: 11708-11718.

[22] LI J, LIU H, XIA J, et al. The impact of electrolyte additives and upper cut-off voltage on the formation of a rocksalt surface layer in $\mathrm{LiNi}_{0.8} \mathrm{Mn}_{0.1} \mathrm{Co}_{0.1} \mathrm{O}_{2}$ electrodes. Journal of The Electrochemical Society, 2017, 164(4): A655-A665.

[23] HONG P, XU M, ZHENG X, et al. Effect of ethylene glycol bis (propionitrile) ether (EGBE) on the performance and interfacial chemistry of lithium-rich layered oxide cathode. Journal of Power Sources, 2016, 329: $216-224$.

[24] YAN X, CHEN C, ZHU X, et al. Aminoalkyldisiloxane as effective electrolyte additive for improving high temperature cycle life of nickel-rich $\mathrm{LiNi}_{0.6} \mathrm{Co}_{0.2} \mathrm{Mn}_{0.2} \mathrm{O}_{2} /$ graphite batteries. Journal of Power Sources, 2020, 461: 228099.

[25] BUBERGER I, SEIDLMAYER S, GASTEIGER H A, et al. Aging analysis of graphite/ $\mathrm{LiNi}_{1 / 3} \mathrm{Mn}_{1 / 3} \mathrm{Co}_{1 / 3} \mathrm{O}_{2}$ cells using XRD, PGAA, and AC Impedance. Journal of The Electrochemical Society, 2015, 162(14): A2737-A2746.

[26] GILBERT J A, SHKROB I A, ABRAHAM D P. Transition metal dissolution, ion migration, electrocatalytic reduction and capacity loss in lithium-ion full cells. Journal of The Electrochemical Society, 2017, 164(2): A389.

[27] TENG X, BAI Y, MA L, et al. In-situ analysis of gas generation in lithium ion batteries with different carbonate-based electrolytes. ACS Applied Materials \& Interfaces, 2015, 7(41): 22751-22755.

[28] YAO W, ZHANG H, ZHONG S, et al. Microwave-assisted synthesis and $\mathrm{Co}$, Al co-modification of Ni-rich $\mathrm{LiNi}_{0.8} \mathrm{Mn}_{0.2} \mathrm{O}_{2}$ materials for Li-ion battery electrode. Journal of Inorganic Materials, 2021, 36(7): 718-732.

[29] KEEFE A S, BUTEAU S, HILL I G, et al. Temperature dependent EIS studies separating charge transfer impedance from contact impedance in lithium-ion symmetric cells. Journal of The Electrochemical Society, 2019, 166(14): A3272-A3279.

[30] LI Y K, CHENG B, JIAO F P, et al. The roles and working mechanism of salt-type additives on the performance of high-voltage lithium-ion batteries. ACS Applied Materials \& Interfaces, 2020, 12: $16298-16307$. 


\title{
补充材料：
}

\section{双功能电解液添加剂对锂离子电池高温高电压性能的影响}

\author{
江依义 ${ }^{1}$, 沈 旻 ${ }^{1}$, 宋半夏 ${ }^{1}$, 李 南 $^{1}$, 丁祥欢 ${ }^{1}$, 郭乐毅 ${ }^{2}$, 马国强 ${ }^{1,2}$
}

(1. 浙江省化工研究院有限公司锂电材料重点实验室, 杭州 $310012 ; 2$. 中国计量大学 光电材料与器件研究院, 杭州 310018)
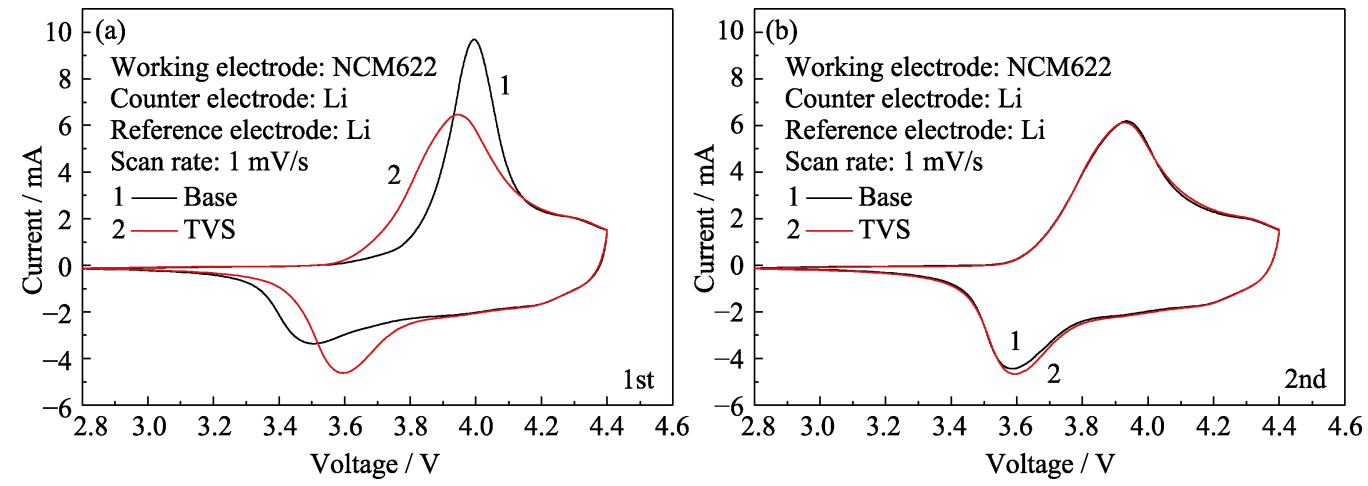

图 S1 对照组和实验组电解液以 NCM622 为工作电极的 $\mathrm{CV}$ 曲线

Fig. S1 CV curves of NMC622 electrodes with and without TVS in electrolytes

(a) 1 st cycle; (b) 2nd cycle

表 S1 实验组和对照组电池经 $4.4 \mathrm{~V} 、 60{ }^{\circ} \mathrm{C}$ 存储 $14 \mathrm{~d}$ 后的气体成分及含量

Table S1 Gas composition and contents of pouch cells with and without TVS in electrolytes stored at cutoff potential of $4.4 \mathrm{~V}$ and temperature of $60{ }^{\circ} \mathrm{C}$ for $14 \mathrm{~d}$

\begin{tabular}{ccccrr}
\hline Sample & $\mathrm{CO} / \mu \mathrm{L}$ & $\mathrm{CH}_{4} / \mu \mathrm{L}$ & $\mathrm{CO}_{2} / \mu \mathrm{L}$ & $\mathrm{C}_{2} \mathrm{H}_{4} / \mu \mathrm{L}$ & $\mathrm{H}_{2} / \mu \mathrm{L}$ \\
\hline Base & 393.3 & 253.2 & 209.3 & 67.0 & 17.6 \\
TVS & 9.2 & 4.8 & 2.2 & 1.1 & 0.2 \\
\hline
\end{tabular}
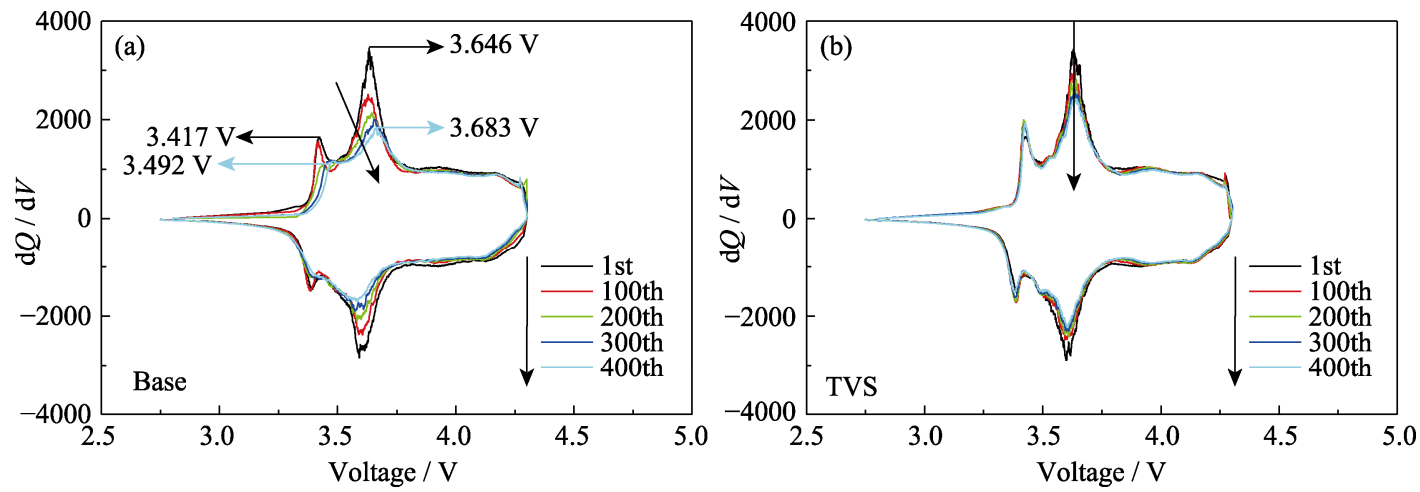

图 S2 对照组和实验组电池在 $45{ }^{\circ} \mathrm{C}$ 的循环性能

Fig. S2 Cycling performance of pouch cells with and without TVS in electrolytes at $45{ }^{\circ} \mathrm{C}$

(a) Differential capacity ( $\mathrm{d} Q / \mathrm{d} V)$ versus potential of Base; (b) Differential capacity $(\mathrm{d} Q / \mathrm{d} V)$ versus potential of TVS 
表 S2 对照组和实验组电池循环 100 周前后及相应的对称电池的 EIS 拟合参数

Table S2 Fitted EIS results before and after 100 cycles of pouch full cells and corresponding symmetric cells with and without TVS in electrolytes

\begin{tabular}{|c|c|c|c|c|c|c|c|c|c|}
\hline \multirow{2}{*}{ Sample } & \multicolumn{3}{|c|}{ Full cell } & \multicolumn{3}{|c|}{ Anode symmetric cell } & \multicolumn{3}{|c|}{ Cathode symmetric cell } \\
\hline & $R_{\mathrm{S}} / \mathrm{m} \Omega$ & $R_{\mathrm{sei}} / \mathrm{m} \Omega$ & $R_{\mathrm{ct}} / \mathrm{m} \Omega$ & $R_{\mathrm{S}} / \mathrm{m} \Omega$ & $R_{\mathrm{sei}} / \mathrm{m} \Omega$ & $R_{\mathrm{ct}} / \mathrm{m} \Omega$ & $R_{\mathrm{S}} / \mathrm{m} \Omega$ & $R_{\text {sei }} / \mathrm{m} \Omega$ & $R_{\mathrm{ct}} / \mathrm{m} \Omega$ \\
\hline Base-before cycle & 16.2 & 7.5 & 14.2 & 3.4 & 4.7 & 23.2 & 2.6 & 116.1 & 21.2 \\
\hline Base-after cycle & 46.7 & 9.1 & 19.3 & 4.2 & 17.1 & 26.5 & 2.7 & 144.3 & 26.7 \\
\hline TVS-before cycle & 16.4 & 8.9 & 25.8 & 4.5 & 20.5 & 43.3 & 2.1 & 86.1 & 18.2 \\
\hline TVS-after cycle & 38.5 & 10.2 & 25.4 & 4.8 & 22.6 & 43.8 & 2.2 & 100.4 & 18.1 \\
\hline
\end{tabular}
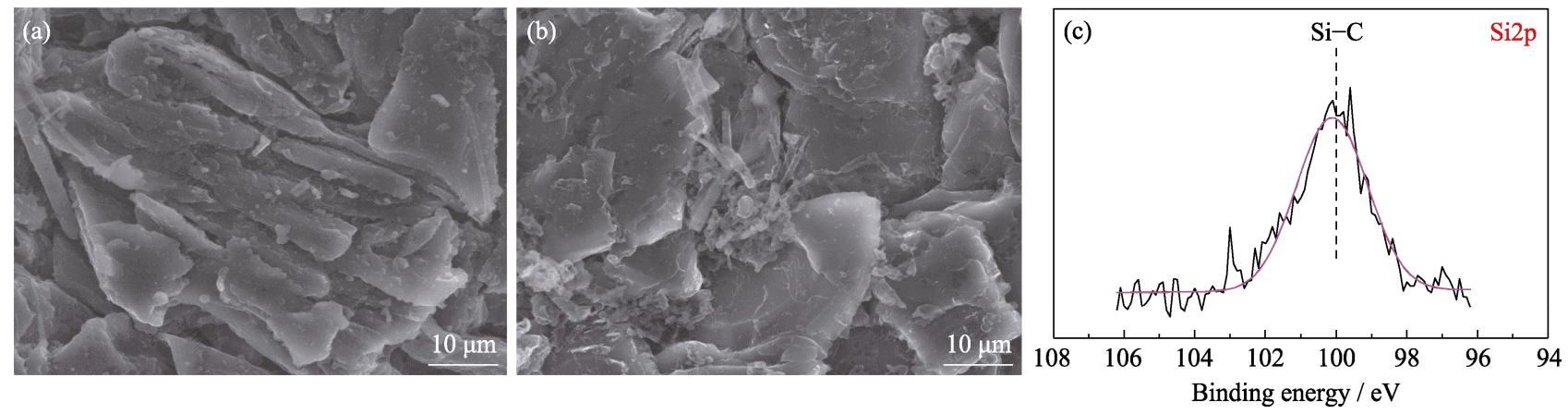

图 S3 (a)对照组和(b)实验组电池循环 100 周后负极 SEM 照片; (c)实验组电池循环 10 周后负极表面 Si2p XPS 分谱 Fig. S3 SEM images of anodes from pouch cells (a) without and (b) with TVS in electrolytes after 100 cycles;

(c) Si2p XPS spectra of anode from pouch cell with TVS in electrolyte after 10 cycles

(a) Cathode

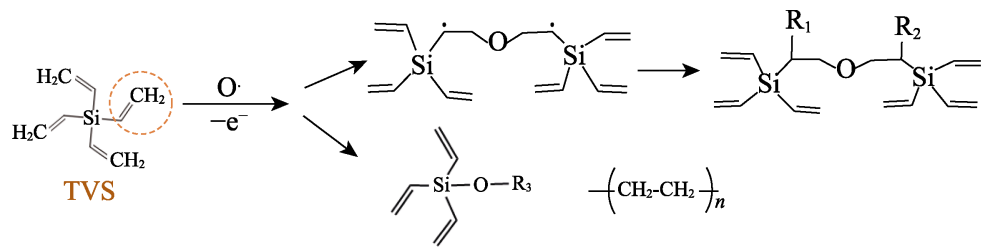

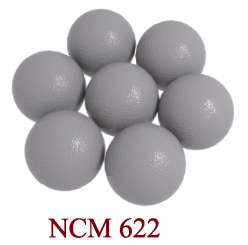

(b) Anode
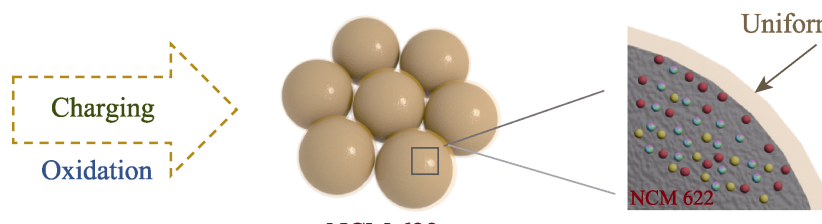

Uniform CEI layer

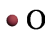

- $\mathrm{Ni} / \mathrm{Co} / \mathrm{Mn}$

NCM 622

$\bullet \mathrm{Li}$
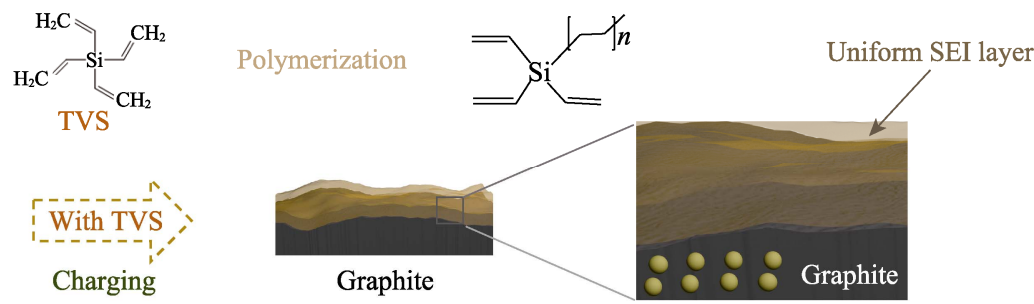

图 S4 TVS 添加剂在 NCM622/石墨软包电池正负极界面的工作机理

Fig. S4 Working mechanism of TVS additive on cathode and anode of NCM622/graphite pouch cell

\section{电池制作信息:}

将 NCM622 材料、聚偏氟乙烯黏结剂、导电炭黑以 $96.5: 2: 1.5$ 的质量比进行混合，以 $N$-甲基吡咯烷 酮为溶剂, 进行充分分散。将制备浆料双面涂覆在铝箔上, 单面活性物质负载量约为 $160 \mathrm{~g} / \mathrm{m}^{2}$, 经过烘干、 冷压、分切、裁片等工艺获得正极片。将石墨、导电炭黑、羧甲基纤维素钠、丁苯橡胶以 $95: 1: 1.5: 2.5$ 
的质量比进行混合, 以水为溶剂, 进行充分分散。将负极浆料双面涂覆于铜箔上, 单面活性物质负载量约为 $92 \mathrm{~g} / \mathrm{m}^{2}$, 经过烘干、冷压、分切、裁片后获得负极片。正极片和负极片间加入隔膜进行卷绕，再经过冷压、 极耳焊接后封装到铝塑袋中, 经过烘烤、密封作为干电芯备用。

软包电池经高温存储后体积变化率(Swelling rate), 内阻变化率(ACR change rate), 自放电率 $(K)$ 和容量恢 复率(Capacity recovery rate)的计算公式分别如式(S1) 式(S4)。

$$
\text { Swelling rate }=\frac{V_{2}-V_{1}}{V_{1}} \times 100 \%
$$

其中 $V_{2}$ 为存储后室温下的体积 $(\mathrm{mL}), V_{1}$ 为存储前室温下的体积 $(\mathrm{mL})$ 。

$$
\mathrm{ACR} \text { change rate }=\frac{\mathrm{ACR}_{2}-\mathrm{ACR}_{1}}{\mathrm{ACR}_{1}} \times 100 \%
$$

其中 $\mathrm{ACR}_{2}$ 为存储后室温下的内阻 $(\mathrm{m} \Omega), \mathrm{ACR}_{1}$ 为存储前室温下的内阻 $(\mathrm{m} \Omega)$ 。

$$
K=\left(\mathrm{OCV}_{1}-\mathrm{OCV}_{2}\right) / \Delta t
$$

其中 $\mathrm{OCV}_{1}$ 为存储前室温下的开路电压 $(\mathrm{V}), \mathrm{OCV}_{2}$ 为存储后室温下的开路电压 $(\mathrm{V}), \Delta t$ 为存储时间 $(\mathrm{d})$ 。

$$
\text { Capacity recovery rate }=\frac{Q_{2}}{Q_{1}} \times 100 \%
$$

其中 $Q_{2}$ 为存储后的放电容量 $(\mathrm{mAh}), Q_{1}$ 为存储前的放电容量 $(\mathrm{mAh})$ 。 